\title{
E-Learning, ICT, and Learning Portals for Schools
}

\author{
Ferran Ruiz Tarragó \\ Government of Catalonia - Department of Education,Spain, fruiz@pie.xtec.es
}

\begin{abstract}
E-learning and learning portals are two closely associated concepts coined mainly outside education. An increasingly powerful industry offers software platforms, digital contents and learning services to commercial companies and academic institutions. Given their goals, design, and content orientation there is concern that e-learning environments are poorly suited to serve school education in many respects: catering for the specific needs of young learners; accommodation of suitability and flexibility features for teachers; compatibility with the schools' experience of learning with and through ICT; and issues of privacy, control and academic freedom. To contribute to overcome such difficulties some specific features and criteria for school learning portals are proposed. Before that the paper revises the origins and rationale of e-learning and briefly considers its impact on university education. It also considers the consolidation of e-learning services through learning portals, and the broad aims and implications of ICT in schools.
\end{abstract}

\section{E-LEARNING IN BUSINESS AND UNIVERSITIES}

\subsection{Learning and training needs of corporations}

The companies and institutions of the information society have to innovate continuously in order to develop and succeed in competitive world markets and in international arenas. Besides equipment and infrastructure, innovation requires substantial and continued investments of an intangible nature, notably in the fields of human resources development, redefinition of labor and hierarchical relationships inside companies, development of information structures and knowledge management. Employees have to learn new concepts and skills, and have to adapt themselves continuously to new assignments, project teams and working environments. This has a strong impact on the training policies of enterprises and corporations. Human

The original version of this chapter was revised: The copyright line was incorrect. This has been corrected. The Erratum to this chapter is available at DOI: 10.1007/978-0-387-35701-0_35 
resources departments need to offer flexible training methods, increase the range of opportunities to facilitate new learning, and provide suitable contents and support at the right moment.

'E-learning' has recently come out as the solution for this huge problem. Across the globe business personnel are using the web to access learning materials and to communicate with colleagues and training tutors at any moment and from any geographical location. Such people are 'e-learners' and 'e-learning' - a term that refers both to technology and methodologyprovides them availability and flexibility that traditional learning and training methods do not offer. It is generally admitted by the business sector that e-learning provides substantial advantages in company training, and that it is more effective than conventional methods at a lower cost, partly because e-learning courses and online training do not require travel and interfere less with working time.

\subsection{The business of e-learning and its components}

Many companies provide e-learning services and products to other business, corporations and institutions. Hardware, software, telecoms, publishing and service companies see education and training as a potentially huge market: e-learning is considered a hot business topic on which many economic expectations are placed. According to a study by International Data Communications (IDC), worldwide spending on e-learning will surpass $\$ 23$ billion USD by $2004 .^{\prime}$ A number of international conferences and 'elearning festivals' are being held, often supported by powerful high-tech corporations and consulting companies. "E-learning is the next major killer application," proclaimed Cisco CEO John Chambers at Comdex in Las Vegas (Moore \& Jones, 2001). The underlying assumption of business people in such forums seems to be that e-learning will deliver workers 'just in time' online knowledge and training at the desktop, which is decisive for increasing productivity and profits.

Education is "an industry that, from a stock market standpoint, didn't exist in any meaningful way five or six years ago" (The ABCs of Education Stocks, 2001). It is mainly composed of textbook publishers, corporatetraining companies, and educational software, content providers and service companies ranging from reliable and valuable leading bluechips to innovative and fragile startups. The economic slowdown actually improves the outlook of this industry because "as unemployment rises, more employees seek to upgrade their skills to sharpen their job prospects" (The ABCs of Education Stocks, 2001).

\footnotetext{
${ }^{1}$ http://www.ffg.com/resource/why-e-learning.asp, September 28, 2002.
} 
E-learning business is a complex economic sector of which content is the key element: without content to be delivered electronically to customers there is no e-learning business. The intellectual knowledge to be offered to users has to be created either from scratch or adapted from existing materials, implemented in the most suitable multimedia format combining texts, graphics, tables, animation, audio, video and simulations, and it has to be localised or customized for specific countries or sectors or clients, using local languages while taking into account cultural issues.

Software is the second main component of e-learning. The online interactions between learners and content materials, the interactions among learners themselves and between students, teachers and tutors, and the access to a variety of administrative and support features are realised through specific software platforms, often referred to as virtual learning environments. Such platforms enable users to submit and retrieve information via a browser, and allow for the activity of tutors and administrators of the system as well. They are leased or sold as 'e-learning solutions' and many companies are engaged in their design, development, and support.

Besides content and software platforms the e-learning industry has other components that can't be considered here but seem worth mentioning because their implications for education and specifically for schools. To name only a few: issues of cost (pay-per-course, pay-per-user, etc.), pricing and taxation for national and international users; issues of copyright, electronic rights and intellectual property, and permission to manipulate the materials; issues of control, privacy and secure use; aspects of content maintenance, standards, bandwidth for correct delivery and user support; and finally the explicit or hidden relationships with the infrastructure side: servers, hosts and operating systems.

\section{$1.3 \quad$ E-learning in companies}

Every company adopting e-learning is likely to develop an e-learning strategy, the main elements of which relate to content and to management. The decision of whether to buy off-the-shelf courseware appropriate to the company's needs or to undertake custom course development is crucial. The former implies matching company needs with suppliers' products, licensing and support, and the latter launches the company into a generally complex process of instructional and interaction design, creation or adaptation of materials, technical implementation, and evaluation and feed-back.

The management of e-learning is frequently linked with the information and administrative systems of the firm using a learning management system or LMS, that is, enterprise-wide software integrated within the human 
resources system to track employee records, web-based training and classroom delivered courses, as well as online course enrollments (Guest \& Juday, 2001). The LMS registers users, monitors online interactions of various kinds, records data from learners, manages the library of courses, handles contents from multiple publishers, and provides reports to the management. Although it usually doesn't include authoring capabilities, it can allow for the development of materials and courses (Kaplen-Leiserson, 2002).

It is worth noting that integrated e-learning environments may allow for the complete surveillance of the employees' learning behaviour: interests and attitudes, performance and levels of attainment, frequency of use, personal profiles, etc.

\section{$1.4 \quad$ E-learning and universities}

The everyday activity of the students in a fast-growing number of universities revolves around computer networks and e-learning. Course descriptions, lecture notes, course content and supplementary materials, assignments, schedules, etc. are available online. E-mail, chat rooms and web surfing are part of the students' everyday life.

The use of information technology in the delivery and practice of higher education is already mandatory in many universities and this could become the general scenario in a mid-term future. As asserted the Vice Chancellor of the University of Melbourne: "e-learning could become the environment in which the majority of human beings are educated beyond the secondary level" (Symonds, 2001). In the developing world the delivery of college education to enormous cohorts of students could be well beyond the reach of conventional education institutions, giving maybe the strongest impetus to elearning in the academic world.

The pressure of the e-learning business mentality on higher education is gaining momentum and conventional universities seem to consider it as a powerful tool to extend their areas of activity and influence. As Business Week points out, "the dot-com bubble may have burst in the world of commerce, but the promise of harnessing the Internet for paradigm-changing growth - and even profits - still thrives in the halls of academia" (Symonds, 2001). This is so because, despite the economic downturn, e-learning is emerging as one of the Internet's most useful applications. E-learning allows universities to broaden the scope of their limited market by selling digitized courses taken from the knowledge of their faculties. In postgraduate studies and further education the economic slump even drives more part-time adult students into e-learning courses provided by universities in as far as they are forced to re-qualify and acquire new degrees. 
The rapid spreading of e-learning in universities is cause for concern in at least two areas. One of them concerns participation and control. As Noble (1998) points out, "the high-tech transformation of higher education is being initiated and implemented from the top down, either without student and faculty involvement in the decision-making or despite it". The generalization of the use of information technology for teaching and learning based on whole-campus learning management systems reinforces the control of university administrators and undermines the autonomy and academic freedom of the faculty. "Once faculty and courses go online, administrators gain much greater direct control over faculty performance and course content than ever before and the potential for administrative scrutiny, supervision, regimentation, discipline and even censorship increase dramatically", puts Noble (1998) bluntly.

The second area of concern is related to the intellectual rights of the authors of content. Online education is to some extent turning university professors into content creators. They are asked to develop materials for digital courses which are designed and implemented in learning portals by technicians or companies and are often paid a flat fee. Authors are compelled to surrender their intellectual rights to the university, which owns and manages them as intellectual capital. In this way the institution capitalizes on the intellectual activity of its most valuable workers. The pre-packaged courses are commodities that can be freely traded. They can be imparted by other professors or by less qualified personnel at a fraction of the cost of the salary of a university professor. The e-learner becomes a consumer of educational products.

These are crucial issues that deserve close scrutiny and debate, and which to some extent can translate into school education.

\section{ONLINE LEARNING PORTALS}

The use of consolidated websites that offer individuals and organizations access to learning services, content and training resources from single or multiple sources, is a defining element of e-learning, both in universities and in the business world. Such 'online learning portals' or 'learning portals' are virtual education and training centers in which the user can get online courses chosen from a structured catalog, may be allowed to personalize his/her learning path, and can receive individualized coaching. Content may be created specifically by the institution or company that runs the learning portal or may come from a variety of providers.

A number of today's online learning portals could be considered as instruments for the delivery of programmed instruction. They provide 
interactive instructional content through sophisticated multimedia presentation techniques. Powerful database systems with huge storage and retrieval capabilities, coupled with efficient and pervasive programming techniques at server and browser levels can manage interactions tailored to the user, based on the analysis and feed-back on student results. Possibly such systems are on the way to fulfilling the wildest dreams of early computer-assisted instruction or computer-managed learning proponents, in terms of performance, scope and completeness. Their social acceptance is increasing by the combined impetus of a powerful industry and huge training needs.

Fortunately, online learning portals also set the scene for a variety of forms of personal communication and interaction through today's fast lowcost communication systems. This allows for substantial improvements over earlier machine-driven CAI approaches.

Most of the learning portals function as for-profit businesses, even in universities, but a fraction of them are based on advertising revenues or are non-profit services funded institutionally. This is often so in the case of learning portals specific for school education that are created and maintained by governments and education authorities, with or without private support. Given their specific objectives, their design should contain features appropriate to the goals of schooling, to the characteristics of young learners, and to the professional activity of teachers.

\section{ICT IN SCHOOLS}

\subsection{The broad aims and implications of ICT in schools}

In its origins e-learning is not an academic term. At the top of the Internet hype of the late 90 's ' $\mathrm{e}$ ' was added as a prefix to many areas of activity. Egovernment, e-commerce, e-procurement, e-learning are some of the terms that popped up without a clear definition, gaining wide acceptance following the popular hold of 'e-mail'. (One may wonder whether 'e' means 'efficient'.) Such terminology is still in common use after the short-lived 'dot com' era. The term e-learning has become well accepted in the business sector and governments use it widely. Maybe it's here to stay but up to now has not been popular in the world of primary and secondary education. Teachers with native languages other than English may be prone to ignore it and its equivalents in their language.

Beyond terminology issues, schools have been getting to grips with exploring, using and even integrating ICT in education at a growing scale and pace since at least the mid-80s. Many individual teachers, school 
departments and even whole schools are applying basic and specific ICT tools and applications across a range of subjects, fostering the participation of students in collaborative projects, and using interactive multimedia curriculum content, often delivered by the Internet.

Big investment and training plans have been and are being deployed at national and local levels. Corresponding with the rising levels of infrastructure, school education is defining, experimenting and assessing ways of accommodating ICT tools and contents in different school situations and within many pedagogical perspectives, and a fair amount of momentum and experience has been gained so far. An illustrative Australian report (Commonwealth Department of Education, Training and Youth Affairs, 2001) states that schools use ICT to enhance teaching and learning in two ways: 1) using technologies to support the development of skills - uses often referred to as 'learning with technology'; and 2) using ICT to support constructivist approaches to learning - uses central to approaches referred to as 'learning through technology'. The complexity of school-deep innovation through ICT is parallel to those of companies because it requires substantial amounts of team-work, revision of beliefs and practices, training, reorganization, management skills, and leadership.

Also according to the same report the range of outcomes the schools consider important are "much broader than those specified in current curriculum frameworks and systemic testing and assessment programmes". Schools seek "to enhance the level of student engagement in their learning by focusing on the needs of individual students, rather than establishing a learning environment that is focused principally on the curriculum" (Commonwealth Department of Education, Training and Youth Affairs, 2001 , p. 85). So automated content delivery for self-instruction is not the core issue as it is in businesses. Researchers have also reported that social competencies of students are enhanced through collaborative modes of learning.

Computer-based cognitive tools and learning environments are often used to enable and facilitate critical thinking and higher-order learning. Although transmitting knowledge to students by means of ICT can play a role, even a significant one, the technologies should be given to learners "as tools for analyzing the world, accessing information, interpreting and organizing their personal knowledge, and representing what they know to others" (Jonassen \& Reeves, 1996). It is worth noticing that within this paradigm the learner is free and at the same time teacher control is not in question, this being compatible with the fact that many students use computers and the Internet a lot on their own initiative, even outperforming teachers. 


\subsection{Issues of structure and resources}

The adoption of e-learning systems and methods in companies is usually driven by their management, which guarantees or facilitates coordination and the supply of information, resources, commitment and leadership. Considerable expense may be devoted to this end. Schools and high schools, as well as universities, do not fit easily into this scheme, for a number of reasons, some of which are structural.

Schools are "professional bureaucracies" (Mintzberg, 1979). The professional character of the activity means that power of decision-making is not exclusively concentrated among the top management of the organization, while diversity of specialization within the profession involves an even distribution of power. Despite the regulations for standardization and the organizational rules, professionals exert a considerable degree of control over their own work - they can't work otherwise. Professionals make decisions about their own actions, and when necessary adopt strategies of evasion and non-intervention. These features give shape to a complex organizational framework that of necessity must maintain a considerable stability if it is to provide a public service which is of great importance and in considerable demand. ICT and e-learning can only thrive if they are compatible with such structural factors derived from the typology of educational organizations and the service they provide (Ruiz Tarragó, 1994). A strong interplay of bottom up and top down approaches is then indispensable.

On the resources side let us only mention that individual schools in general find it difficult to devote time, money and intellectual energy to plan for ICT and students' e-learning. They are short of personnel to plan and implement them, and they are not able to pay extra bills for external consulting and services, so innovation in this field is really difficult. In this context, the supply of suitable and specific e-learning services for schools may be of great help.

\section{LEARNING PORTALS FOR SCHOOLS}

\subsection{The young e-learner}

We have commented on the key role that content plays in e-learning in companies. Such content is to be used by adult professionals and employees. They are generally assumed to have ample capabilities of independent study and of setting long-term goals. But young learners do not share such characteristics. It can be confidently stated that school students don't need 
nor feel the need to track courses in an online catalog, that their learning doesn't depend on doing automated courses, nor is their learning activity in schooling years going to take place independently, away from teachers, companions and parents. Although self-testing by means of a computer may be helpful, it is nevertheless of limited importance. School students are certainly not in the business of just-in-time learning for retraining and skills improvement.

The long-term vision, autonomy and commitment of the young learner cannot be guaranteed, and even high school students do not share some of the maturity characteristics that are expected in university students. Moreover, the coaching and human guidance of the teacher cannot be automated. Even in the case that the output of day-to-day school teaching resulting from the intellectual labor of teachers could be packaged and marketed as a commodity, it would have limited practical value because the young learner needs to be continuously stimulated, monitored and supported by physically present teachers. No savings seem to be possible if human care, quality and public service are to be maintained. Some differences between universities and schools in this respect may perhaps exist.

Given all those specific characteristics maybe it would be useful to use a formulation of e-learning specific to school education. It should place students and teachers first and well above content, teachers should recognize it as close to their professional role and related to their experience of ICT. It should also convey academic freedom and professional discretion, understood as the power of the teacher to lead or accompany the student according to his or her own judgment, overriding when needed any technical system.

The school e-learner would thus be any pupil who, with the guidance and support of the teacher, in a variety of learning approaches and situations, and having different levels of autonomy, uses ICT and the Internet to some extent: to work with suitable productivity tools or specialized environments; to access, retrieve and process digital content for study and learning purposes; and to communicate or to interact with teachers, tutors, other learners or experts.

This concept may prove compatible with the broad issues and implications of ICT in schools because it emphasizes the roles of the learner and the teacher. Correspondingly learning portals for school education should accommodate fully the needs of the young learner as well as those of the teacher. 


\subsection{Specific features of a learning portal for schools}

Based on the ideas above, we introduce a few characteristics that could be useful to consider when designing a learning portal for school education. Such features, which are being implemented on the learning portal for students, www.edu365.com, of the Department of Education of Catalonia, aim at defining a common working environment for teachers and students.

Teacher repository. The learning environment should provide every teacher with facilities to create, manage, index and retrieve his or her own private digital repository of teaching instruments: lesson plans, exercises, notes, documents, readings, assignments, formulae, tests and exams, computer programs, URLs, databases, multimedia files, etc, irrespective of their format, volume and completedness. Maintaining such a private repository is not to be confused with courseware authoring, activity that should by no means be mandatory. The teacher neither is nor should be a digital content designer - although he/she could eventually become one if he or she wants to - nor be obliged to make use of pre-established content.

Students' grouping. Dynamic grouping of students should be made very easy in order to facilitate the assignment of specific tasks and collaborative projects and to cope with diverse students' needs. Groups could be made with pupils from within the classroom, from other classrooms of the school, or even with students from other schools, with teachers' prior agreement.

Design and assignment of activities. The environment should allow teachers to design curriculum activities for pupils with just a few keystrokes or mouse clicks, using materials chosen from their personal repository or selecting them from any other source, including pre-packaged e-learning courseware. It should allow for the assigning of activities to individual pupils or groups of students and for receiving their input whenever appropriate. It ought not to impose frequency of use nor imply that the activities of the students have to be computer-based. E-learning in schools doesn't mean and shouldn't imply always working online. The system should provide to all its users facilities for online and offline, synchronous and asynchronous activities.

Learning agenda. The system should facilitate for both teachers and students the cooperative management of individual agendas, allowing the students to keep track of their assignments, classroom events (exams, group activities, etc.) and homework. Whenever appropriate it should be a communication tool to inform families about their children's regular assignments, learning and school events.

Personal desktop. The learning portal should provide every user with a personal digital desktop furnishing communication and groupwork facilities, productivity tools for working with information, personal working space and 
a storage area on the server for the management of personal files and web pages. Either online or offline, the browser should be the only computer software needed to use the desktop.

Personal interface. It should cater for age and school levels, personal interests and profiles of any user of the learning portal.

\subsection{Users' privacy}

This is a key issue that should be taken into account in learning portals for schools. By design they have to ensure that activities and interactions of teachers and students are private: they belong to them and to nobody else. No-one should see the students' contributions against the wishes of their teachers. Exchanges should not be known by other teachers not involved with the student nor by the school administrators, unless authorized by the teacher in charge of the student. Administrative monitoring of the teachers' use of the e-learning system by school boards, principals or department heads should not be permitted, except for formal inspection procedures developed according to pre-established and public criteria.

The use of electronic systems for communication between teachers and parents regarding homework assignments, students' performance, etc. that may be the subject of a school policy, is to be distinctly separate from the electronic interaction between student and teacher, which should not be made public without previous agreement.

The digital productions of the students such as projects, designs, writings, messages and files belong to them, are their intellectual property. Therefore nobody should be allowed to seize students' work irrespective of its intrinsic value. Similarly, any content created by teachers is their property, and academic authorities should not be allowed to oblige teachers to transfer or make public the instruments, interactions and results of their job, except when this is legally permissible.

For widespread and long-term use of the system, teachers and students have to be confident of its reliability and its intimacy, so that nobody except the intended recipient can see their actions, ideas and feelings.

\section{CONCLUSION}

We end the paper by quoting an internal report of the European Schoolnet:

The voice of education is not always heard. Education users do not articulate their needs: tools and services developed for consumers, business and universities need considerable modification before they are 
suitable for young learners. (Equipped, trained ... and now what? Trends and issues in elearning in European school systems, 2002)

ICT in schools is much broader than e-learning, and young e-learners are different from adults. Content and services for schools should be driven by the demands of teachers and students, not by the needs of industry. Teachers' discretion and freedom should not be restricted by technical factors but, under teachers' control, such technical capacities may be most relevant to learning. This paper aims to foster the debate over such issues.

\section{REFERENCES}

Commonwealth Department of Education, Training and Youth Affairs (2001). School Innovation: Pathway to the Knowledge Society. Canberra: Commonwealth of Australia.

Equipped, trained ... and now what? Trends and issues in elearning in European school systems. (2002). European Schoolnet, 3 September.

Guest, S. \& Juday, J. (2001). Guidelines for Buying E-learning Services. Learning Circuits, November. Online magazine of American Society for Training \& Development (ASTD). Retrieved from http://www.learningcircuits.org/2001/nov2001/guest.html

Jonassen, D. \& Reeves, T. C. (1996). Learning with technology: Using computers as cognitive tools. In D. Jonassen (Ed.), Handbook of Research for Educational Communications and Technology (pp. 693-719). New York: Simon \& Schuster Macmillan.

Kaplan-Leiserson, E. (2002). E-learning Glossary, Learning Circuits. Online magazine of American Society for Training \& Development (ASTD). Retrieved from http://www.learningcircuits.org/glossary.html

Mintzberg, H. (1979). The Structuring of Organizations. Englewood Cliffs, NJ: Prentice-Hall.

Moore, C. \& Jones, M. (2001). Comdex: E-learning takes stage as next killer app. Retrieved 15 November 2001, from http://www.infoworld.com/articles/hn/xml/ 01/11/15/011115hnelearnmantra.xml

Noble, D. F. (1998). Digital Diploma Mills: The Automation of Higher Education. Retrieved from http://www.firstmonday.dk/issues/issue3_1/noble/

Ruiz Tarragó, F. (1994). The integration of new technological environments in education. Educational Media International, 3l(1), March.

Symonds, W. (2001). Giving It the Old Online Try. Business Week Online, 3 December. Retrieved from http://www.businessweek.com/magazine/content/01_49/b3760072.htm

The ABCs of Education Stocks (2001). Business Week Online, September 24. Retrieved from http://www.businessweek.com/magazine/content/01_39/b3750057.htm 